\title{
Lasagna $^{\mathrm{TM}}$ Soil Remediation
}

\section{INNOVATIVE TECHNOLOGY SUMMARY REPORT}

demonstrated at

U.S. Department of Energy

Cylinder Drop Test Area

Paducah Gaseous Diffusion Plant

Paducah, Kentucky

prepared for

U.S. Department of Energy

Office of Environmental Management

Office of Science and Technology

April 1996

DISTRIBUTION OF THIS DOCUMENT IS UNLIMITED 



\section{TABLE OF CONTENTS}

1 SUMMARY

page 1

2 TECHNOLOGY DESCRIPTION

page 4

3. PERFORMANCE

page 7

4 TECHNOLOGY APPLICABILITY \& ALTERNATIVES page 9

$5 \quad \cos T$

page 10

6 REGULATORY/POLICY ISSUES

page 11

7 LESSONS LEARNED

page 12

APPENDICES

A References 



\section{DISCLAIMER}

Portions of this document may be illegible in electronic image products. Images are produced from the best available original document. 



\section{SECTION I}

\section{SUMMARY}

\section{Technology Description}

Lasagna ${ }^{\mathrm{TM}}$ is an integrated, in situ remediation technology being developed by an industrial consortium consisting of Monsanto, E. I. DuPont de Nemours \& Co., Inc. (DuPont), and General Electric, with participation from the Department of Energy (DOE) Office of Environmental Management, Office of Science and Technology (EM-50), and the Environmental Protection Agency (EPA) Office of Research and Development (Figure 1).

Lasagna ${ }^{\mathrm{TM}}$ remediates soils and soil pore water contaminated with soluble organic compounds. Lasagna ${ }^{\top M}$ is especially suited to sites with low permeability soils where electroosmosis can move water faster and more uniformly than hydraulic methods, with very low power consumption. The process uses electrokinetics to move contaminants in soil pore water into treatment zones where the contaminants can be captured or decomposed. Initial focus is on trichloroethylene (TCE), a major contaminant at many DOE and industrial sites. Both vertical and horizontal configurations have been conceptualized, but fieldwork to date is more advanced for the vertical configuration. Major features of the technology are

- electrodes energized by direct current, which causes water and soluble contaminants to move into or through the treatment layers and also heats the soil;

- treatment zones containing reagents that decompose the soluble organic contaminants or adsorb contaminants for immobilization or subsequent removal and disposal; and

- a water management system that recycles the water that accumulates at the cathode (high pH) back to the anode (low pH) for acid-base neutralization. Alternatively, electrode polarity can be reversed periodically to reverse electroosmotic flow and neutralize $\mathrm{pH}$.

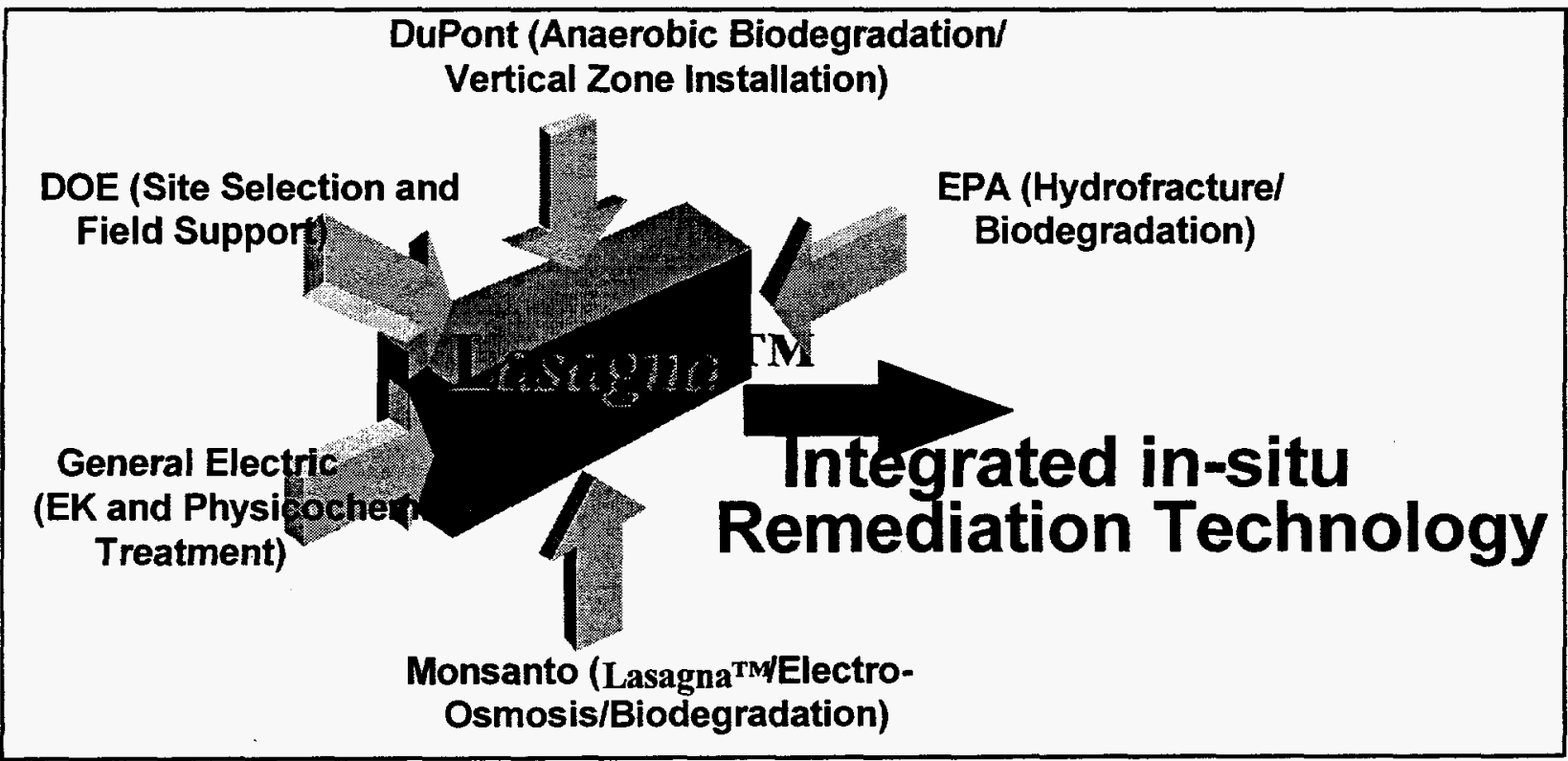

Figure 1. Major components of the Lasagna ${ }^{\mathrm{TM}}$ technology. 
A proof-of-concept field demonstration was conducted at the Paducah Gaseous Diffusion Plant in Paducah, Kentucky.

\author{
U. S. Department of Energy \\ Paducah Gaseous Diffusion Plant (PGDP) \\ Cylinder Drop Test Area (SWMU 91) \\ Paducah, Kentucky \\ January 1995 through May 1995
}

The demonstration was sponsored by the DOE EM-50 Industrial Program through the Morgantown Energy Technology Center.

The PGDP site consists of a 4-ft layer of gravel and clay overlaying a 40-ft layer of sandy clay loam with interbedded sand layers. The clay soil had been contaminated with TCE at concentrations ranging from $1 \mathrm{ppb}$ to $1760 \mathrm{ppm}$. Because of its very low organic content, the soil adsorbed very little TCE. The zone to be remediated measured $15-\mathrm{ft}$ wide by $10-\mathrm{ft}$ across and $15-\mathrm{ft}$ deep, with average contamination of $83.2 \mathrm{ppm}$. The highest TCE concentrations $(200-300 \mathrm{ppm})$ were found $12-16 \mathrm{ft}$ below the surface. Steel panels were used as electrodes and the treatment zones consisted of wick drains containing granular activated carbon to adsorb the TCE. A plastic-wrapped shed was built above the test area, and a vent fan directed soil off-gas to an in-line filter for TCE capture.

Two patents covering the technology have been granted to Monsanto, and the term Lasagna ${ }^{\mathrm{TM}}$ has also been trademarked by Monsanto. Developing the technology so that it can be used with assurance for site remediation is the overall objective of the sponsoring consortium.

\title{
Key Results
}

- Soil samples taken throughout the test site before and after the test indicated an average removal efficiency of $98 \%$ for TCE, with some samples showing greater than $99 \%$ removal. TCE soil levels were reduced to an average concentration of $1.2 \mathrm{ppm}$.

- Flow rate by electroosmosis was $4 \mathrm{~L} / \mathrm{h}$, and three pore volumes of water (between adjacent treatment zones) were transported during the 4-month operating period.

- Dense, non-aqueous-phase liquid (DNAPL) locations were cleaned to 1-ppm levels except for a 15-ft deep sample that was reduced to $17.4 \mathrm{ppm}$ (Note that because treatment zones were only 15 -ft deep, diffusion from untreated deep zones may have contributed to the 17.4-ppm result.)

- A TCE mass balance at test conclusion accounted for about $50 \%$ of TCE. Differences may be a result of passive diffusion (5\%), evaporation (5\%), in situ degradation of TCE during the test, or incomplete extraction of TCE from the activated carbon prior to analysis. About $20 \%$ (12 of 64) of the wicks were sampled. Given the highly nonuniform TCE concentrations in the soil and the limited sampling, a mass balance of $50 \%$ is an excellent result.

- Based on the initial field tests, treatment costs for a typical 1-2-acre site with contamination to a depth of $40-50 \mathrm{ft}$ were estimated to be about $\$ 50-\$ 90 / \mathrm{yd}^{3}$ of treated soil.

\section{Phase II}

A commercial-scale development demonstration (Phase lla) is planned for the Paducah site in 1996, using iron filings in the treatment zones to dechlorinate the TCE in situ. The goal is to reduce soil contamination to $5.6 \mathrm{ppm}$ or less in the $20 \mathrm{ft} \times 30 \mathrm{ft} \times 45$ - $\mathrm{ft}$ deep treatment zone. If successful, this will be followed by a 
full-scale first application demonstration (Phase II) encompassing the entire contaminated region (105 $\mathrm{ft} x$ $60 \mathrm{ft} \times 45$-ft deep), with treatment accomplished in 12 to 24 months.

\section{Contacts}

\section{Technical}

Sa V. Ho, Principal Investigator, Monsanto, (314) 694-5179

Steven C. Meyer, Project Manager, Phase IIA, Monsanto Enviro-Chem, (314) 275-5946

Joseph J. Salvo, General Electric, (518) 387-6123

Stephen H. Shoemaker, DuPont, (713) 586-2513

\section{Management}

Skip Chamberlain, DOE EM-50 Program Manager, (301) 903-7248

Dave Biancosino, DOE EM-50 Program Manager, (301) 903-7961

Jim Wright, DOE Plume Focus Area Manager, (803) 725-5608

Kelly Pearce, DOE Contract Representative, (304) 285-5424

\section{Paducah Site Support}

Myrna Redfield, DOE EM-40 Program Manager, (502) 441-6815

Fraser Johnstone, Lockheed Martin Energy Systems Project Manager, (502) 441-5077

Jay Clausen, Lockheed Martin Energy Systems Technical Manager, (502) 441-5090 


\section{SECTION 2}

\section{TECHNOLOGY DESCRIPTION}

\section{Vertical Process Schematic}

The Phase I field test of Lasagna ${ }^{T M}$ had electrodes and treatment zones arranged as shown in Figure 2. DuPont and its subcontractor, Nilex Corporation, used an oversized mast and mandrel system to accommodate carbon-filled wick drains 18 -in. wide by 2 -in. thick. The wick drains were made by wrapping permeable geotextile fabric around a spacer material to create a conduit for groundwater flow. A wick was installed by inserting it through the steel emplacement mandrel that had been driven into the soil to the desired depth using a 10-ton vibratory hammer (Figure 3). A steel drive shoe placed over the leading edge of the hollow mandrel facilitated penetration to a depth about $15 \mathrm{ft}$ below grade. Steel plate electrodes and geomembrane insulating panels were emplaced using the same mandrel.

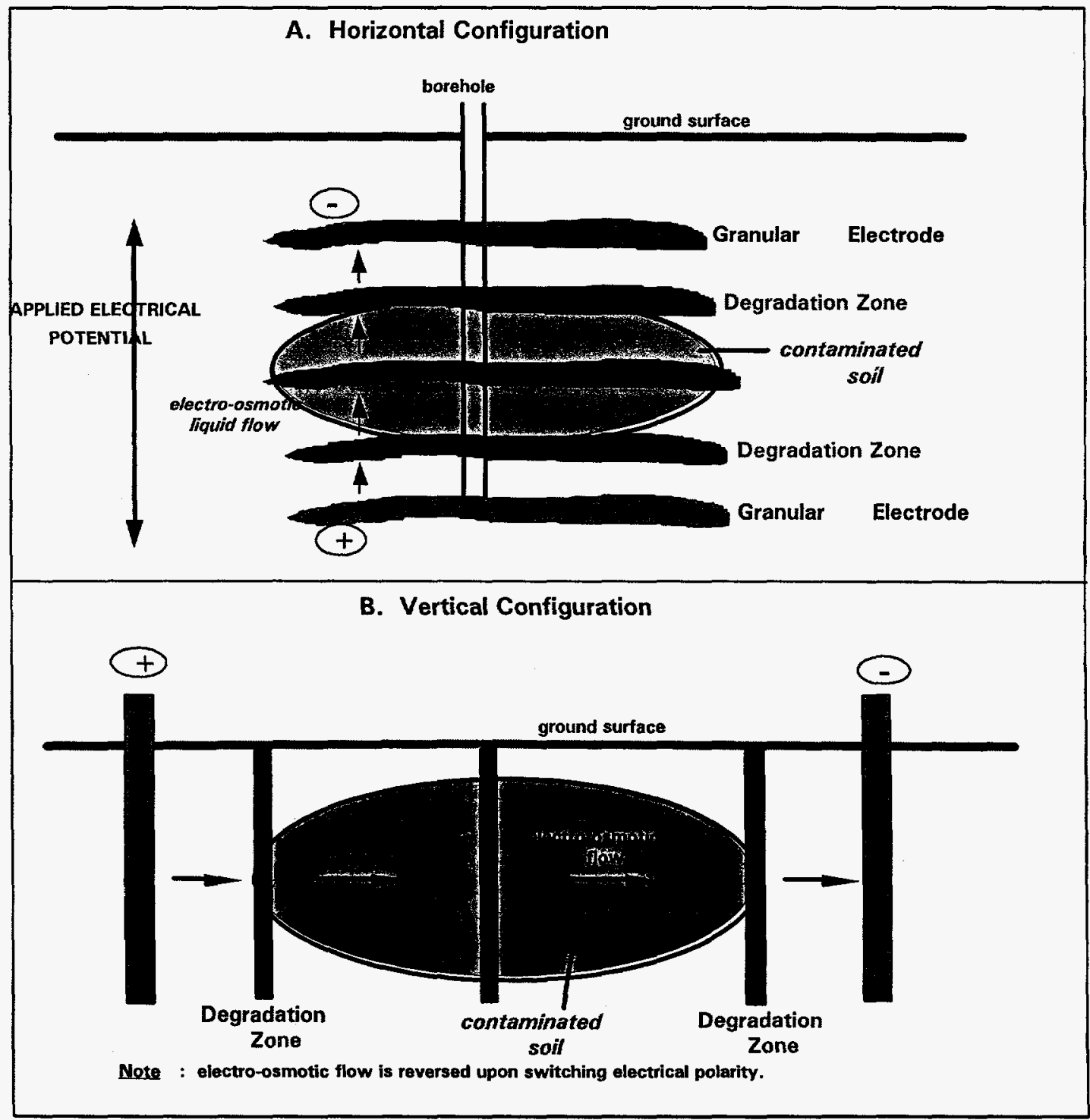

Figure 2. Horizontal and vertical Lasagna ${ }^{\mathrm{TM}}$ configurations. 


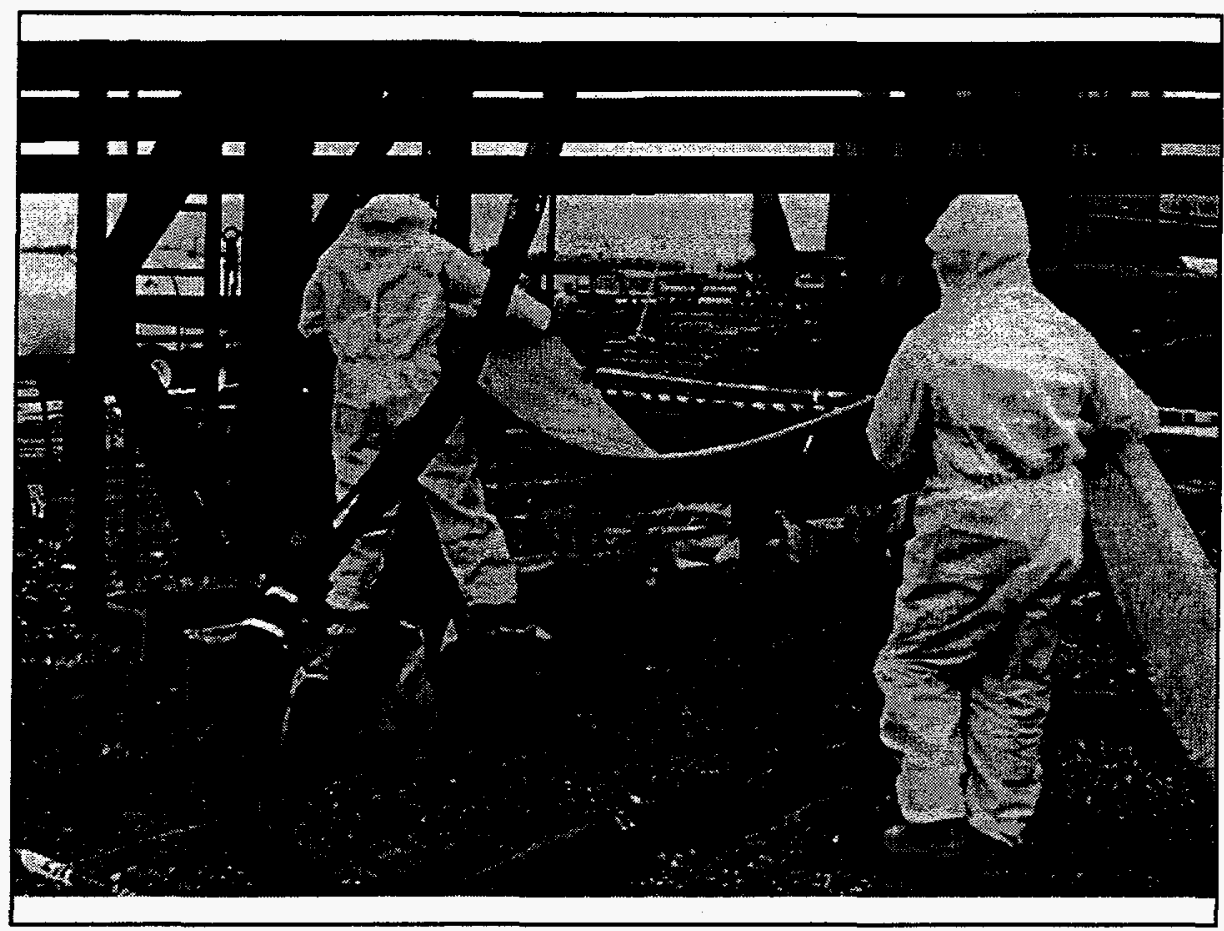

Figure 3. Wicks being installed in hollow mandrel.

The treatment zones were installed with layers of soil 21 -in. thick between each zone. Two wicks in each row contained a special sampling cassette that could be retrieved for TCE analysis during or after the experiment. A wick with a sampling cassette was also installed in the control zone at the west end of the unit, and this zone was isolated hydraulically by a surrounding wall of sheet piling.

\section{Operating Characteristics of Phase I Demonstration}

Initial power

Power after one month Electroosmotic flow rate Initial soil temperature Temperature at test end
138 volts, 41 amperes

105 volts, 40 amperes (remained stable at this level)

4-5 L/h

$15^{\circ} \mathrm{C}$ (at the 10-ft depth)

$45.2^{\circ} \mathrm{C}$ (at the core, the hottest spot),

$25-30^{\circ} \mathrm{C}$ (average soil temperature)

Electroosmotic conductivity, $\mathrm{pH}$, conductivity trends, power requirements, temperature trends, and operational stability were predicted from laboratory and pilot-scale experiments and mathematical modeling and then confirmed in the field.

\section{Phase lla Treatment Plan}

Phase lla, scheduled to begin in June 1996, will modify the Phase I configuration by using zero-valent iron in the treatment zones to chemically reduce TCE to non-toxic end products-chloride ion, ethane, ethene, and other hydrocarbons. Laboratory studies by General Electric have shown that reduction rates are considerably enhanced by increasing temperature, making the soil heating that accompanies Lasagna ${ }^{\mathrm{TM}}$ an added benefit. Phase lla will also test the ability of the technology to work at greater depth-45 $\mathrm{ft}$-and will assess the use of wider spacing (up to $7 \mathrm{ft}$ ) between treatment zones to reduce costs.

Features of Phase lla include the following:

- The test plot will be $20 \mathrm{ft} \times 30 \mathrm{ft} \times 45 \mathrm{ft}$ deep. 
- Electrodes will be 30 vol \% iron filings mixed with $70 \%$ carbon (coke) granules ( 46 wt \% iron and $54 \%$ coke on dry weight basis).

- Treatment zones 2 -in. thick will be $8 \%$ by volume iron filings mixed with kaolin clay ( $35 \mathrm{wt}-\%$ iron and $65 \%$ clay on dry weight basis).

- The spacing array will be electrode $<--7 \mathrm{ft}-->|<--5 \mathrm{ft}->|<--2 \mathrm{ft}-->\mid<--7 \mathrm{ft}-->$ electrode (where $\mid$ represents the treatment zone).

- The Nilex mandrel will be driven, filled with slurry (no wicks), and the mandrel removed.

- $\quad$ An in situ probe will periodically measure TCE concentration as treatment progresses.

- Phase lla will operate 3-6 months to obtain data for a go/no-go decision on the complete Phase II. Target levels of $5.6 \mathrm{ppm}$ TCE will not be reached in Phase lla, and treatment of this zone would continue as part of Phase II.

If the full Phase II treatment goes forward, a test array, about $105 \mathrm{ft} \times 60 \mathrm{ft} \times 45$-ft deep will be used over a time span of 12 to 24 months. Cost objectives include a treatment cost of $\$ 50-\$ 90 / y d^{3}$. Costs are expected to be lower if treatment time can be extended, thereby permitting use of fewer treatment zones (wider spacing) and/or less electrical power. More economical emplacement methods (e.g., jet grouting) could also reduce treatment costs. 


\section{PERFORMANCE}

\section{Phase I Treatment Performance}

This first field experiment demonstrated the following aspects of Lasagna ${ }^{\mathrm{TM}}$ technology.

- Electroosmosis can effectively transport groundwater contaminated by TCE to treatment zones where TCE is captured by adsorption on activated carbon.

- More than $98 \%$ of TCE can be removed from soil after just three pore volumes of water have been moved between adjacent treatment zones. Sampling of one wick showed that most TCE was captured after the first two pore volumes. Except at very low depths, little additional TCE was trapped by the third pore volume.

- The probable presence of residual DNAPL was indicated by pretest soil samples that showed TCE concentrations greater than $225 \mathrm{ppm}$. In these likely DNAPL locations, TCE levels were reduced to less than $1 \mathrm{ppm}$ (except for a deep sample near the untreated zone that was reduced to $17.4 \mathrm{ppm}$ ), indicating that Lasagna ${ }^{\mathrm{TM}}$ technology could be effective for DNAPL TCE.

TCE removal from the soil is summarized in Figure 4 by results of the pretest and posttest analyses of soil cores. Very high and uniform removal of TCE from the treated soil between 4- and 15-ft depths is indicated. The location of the bore holes can be seen in the map of electrodes and treatment zones (Figure 5). Soil samples taken either outside of or deeper than the test zone (below $15 \mathrm{ft}$ ) showed substantial amounts of TCE present. This sharp contrast demonstrates the remarkable effectiveness of Lasagna $^{\mathrm{TM}}$ treatment.

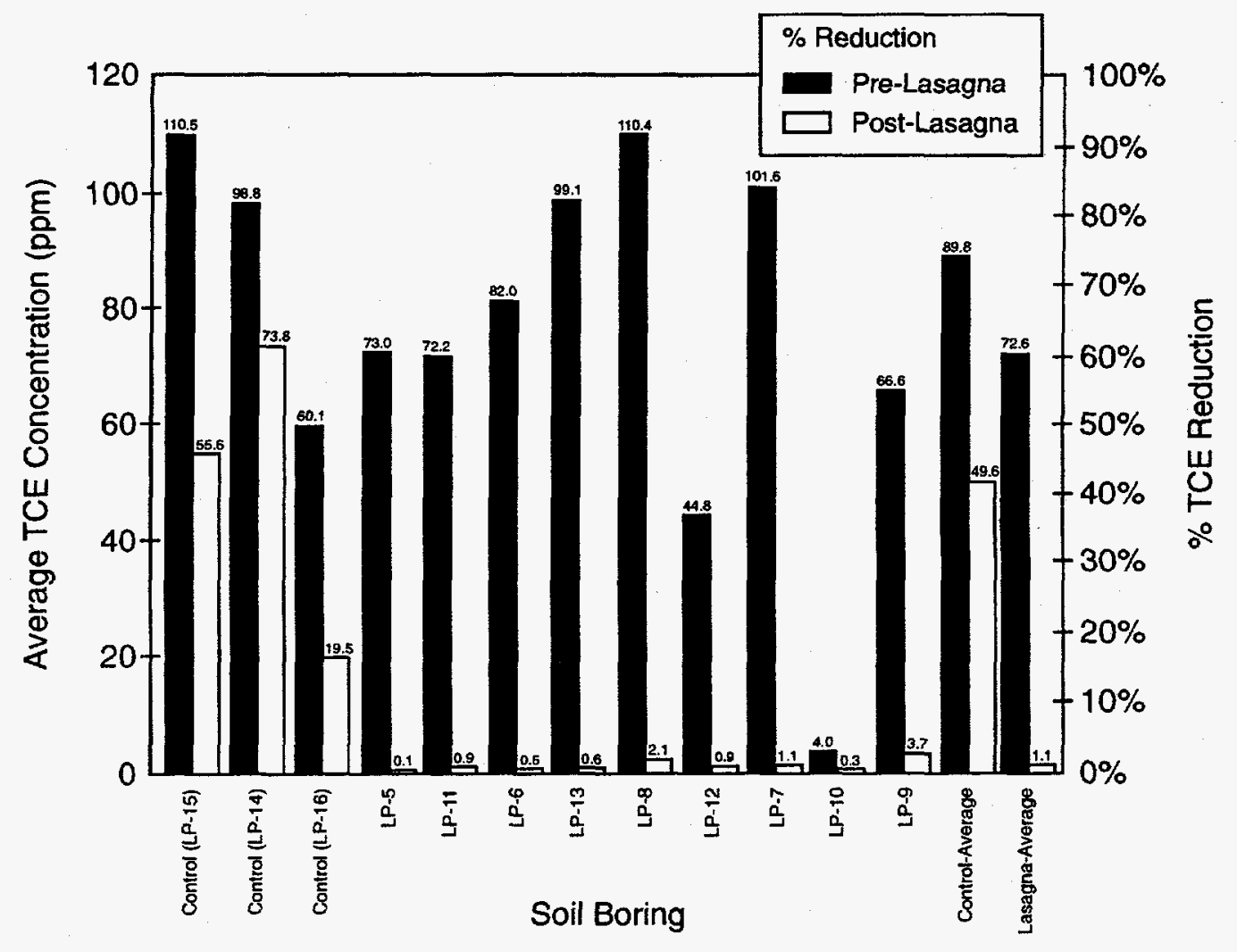

Figure 4. Average trichloroethylene (TCE) concentrations pre- and post-Lasagna ${ }^{\mathrm{Tm}}$. 


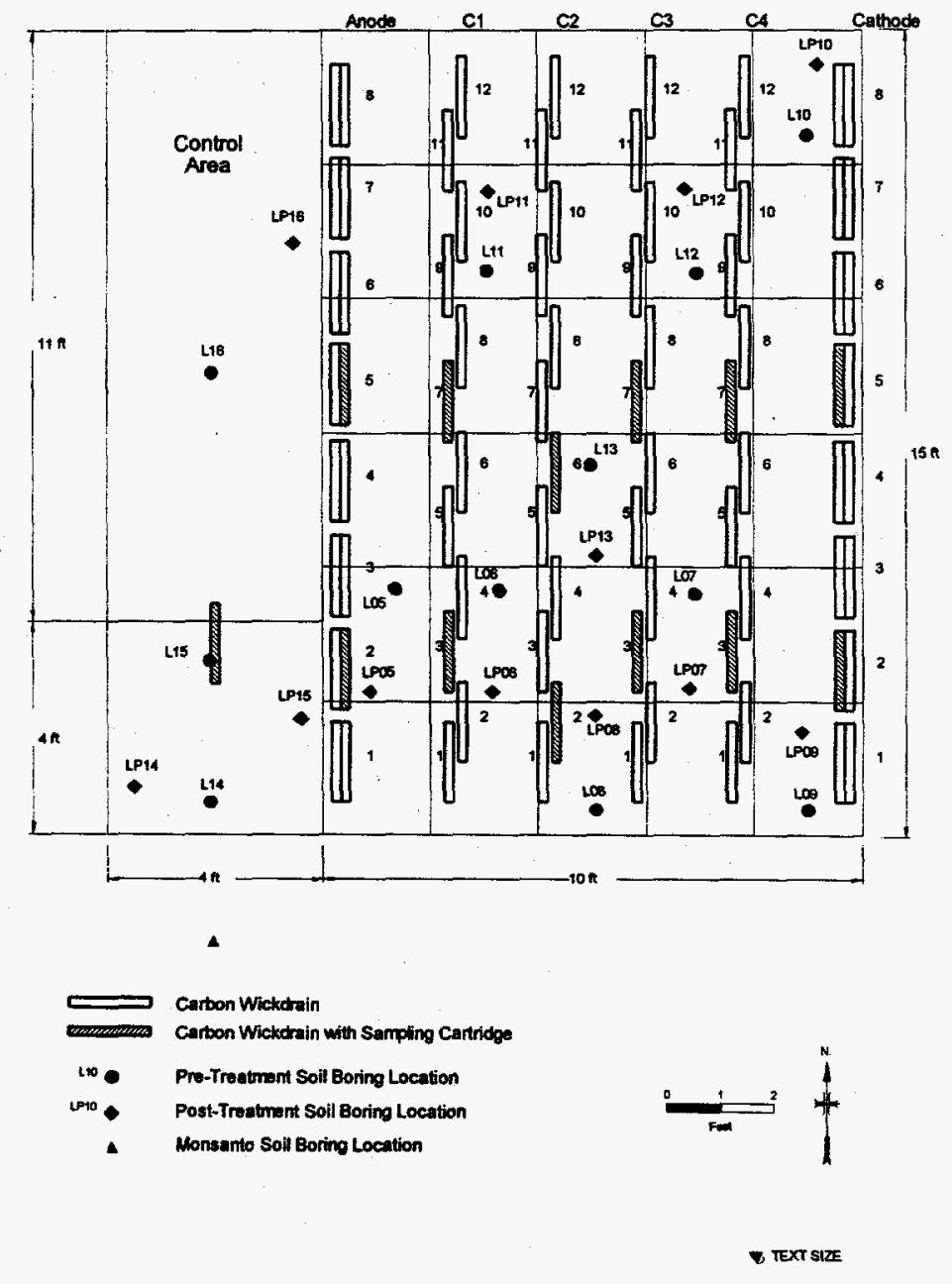

Figure 5. Locations of core samples from the Phase I Lasagna ${ }^{\mathrm{TM}}$ field experiment. 


\section{TECHNOLOGY APPLICABILITY'AND ALTERNATIVE TECHNOLOGIES}

\section{Technology Applicability}

- Low permeability soils with water-soluble contaminants (organics, inorganics, or mixed wastes) could be remediated using Lasagna ${ }^{\mathrm{TM}}$ technology.

- Field experiments at PGDP are staged to quantify performance variables and determine cost effectiveness for in situ TCE remediation.

- Phase I results indicate that electroosmosis can remove residual DNAPL TCE from soil, with concentrations reduced to approximately $1 \mathrm{ppm}$ after 4 months of treatment.

- Phase II tests will evaluate in situ degradation of TCE by reaction with zero-valent iron and the compatibility of this process with electroosmotic transport.

\section{Competing Technologies}

For contaminants in low permeability soils, removal or destruction of the contaminants is generally made difficult by the slow, nonuniform transport of water or air through the soil. This limits the effectiveness of other in situ methods such as pump and treat, vapor extraction, or bioremediation.

A number of soil heating/vapor extraction technologies have been demonstrated at DOE sites (some on soils of low permeability), with treatment cost estimates ranging from $\$ 65 / y d^{3}$ (DOE 1995a), to $\$ 88 / y d^{3}$ (DOE 1995b), to $\$ 123 / \mathrm{yd}^{3}$ (Dev and Phelan 1996). (The referenced reports should be consulted for details.)

Barriers that prevent the further spread of contaminants may be effective remedies in cases where drinking water supplies are not endangered by the contamination. However, once a plume is identified and characterized, public pressure often demands that the offending source be removed or destroyed. Also, barrier technology for plumes has not yet been shown to be feasible, effective, or cost-efficient. (Freeze and McWhorter)

Use of treatment zones for in situ destruction of contaminants gives Lasagna ${ }^{T M}$ a competitive advantage over other electrokinetic methods that extract contaminants for aboveground treatment or disposal. Because treatment zones eliminate the need for aboveground waste handling, and are presumably cheaper to make and install than electrodes, their use imparts cost advantages.

In situ chemical oxidation with reagents such as potassium permanganate or hydrogen peroxide has been proposed as a way of degrading DNAPLs in situ, with reagent delivery accomplished by soil mixing or fracturing in conjunction with oxidant solution injection. Cost estimates of $\$ 130$ to $\$ 200 / \mathrm{m}^{3}$ have been made for the technology based on limited full-scale data (TCE treated with hydrogen peroxide at $80 \%$ removal efficiency) (Gates, Korte, and Siegrist). A recently issued report summarizes the results of the demonstration of in situ soil mixing for volatile organic contaminant remediation that was conducted at the Portsmouth, Ohio, DOE site (DOE 1996). 


\section{SECTION 5}

\section{Cost}

\section{Introduction}

DuPont has completed an engineering evaluation and cost analysis of the vertically configured Lasagna ${ }^{\mathrm{TM}}$ treatment process using a cost optimization model. Input parameters included soil properties, depth of contamination, cost for emplacing electrodes and treatment zones, required purge water volume, cleanup time, and cost of electrical power. For TCE contamination in clay, costs are estimated to range from $\$ 40$ to $\$ 90 / \mathrm{yd}^{3}$ of soil for a 1 -acre site.

The cost-optimized electrode spacing for electroosmosis is $3-6 \mathrm{~m}$ for most soils. This allows cleanup within a reasonable time (less than 5 years) while avoiding soil overheating. Electrode construction is a major factor in overall application cost-generally 20 to $40 \%$. Lasagna ${ }^{\mathrm{TM}}$ reduces the cleanup time and power input by inserting treatment zones between the electrodes. The ability to emplace treatment zones and electrodes in relatively close spacing and at reasonable cost is critical to the cost-effectiveness of the technology.

The technology implementation cost for Lasagna ${ }^{\mathrm{TM}}$ as conducted in the Phase I test (steel plate electrode with wick drains and carbon-filled treatment zone) is estimated at $\$ 80-\$ 90 / y d^{3}$ for remediation in 1 year, $\$ 50-\$ 60 / \mathrm{yd}^{3}$ if 3 years are allowed for remediation. Comparable estimates for the Phase II mode of operation are $\$ 60-\$ 70$ ( 1 year) and $\$ 40-\$ 50$ (3 years). Deeper contamination, although involving more technically challenging emplacement, costs less because of the larger volumes remediated per area of electrode.

A hypothetical case wherein mass-produced, prefabricated materials were emplaced by the mandrel technology was also considered by DuPont. This best possible case lowered implementation costs to $\$ 30-\$ 40$ (1-year case) and $\$ 20-\$ 30$ (3-year case), depending on the depth of contamination. Wide adoption of the technology would presumably be needed to stimulate the development of these new materials.

In all of the above cases, only the direct costs associated with technology application are included. Additional variable costs related to licensing fees, site costs imposed because of regulations, analytical costs, etc. are not included.

\section{Cost Savings Versus Alternative Technologies}

DuPont has benchmarked a number of in situ technologies over the last 3 years. These include

- in situ treatment zones using iron filings for dehalogenation of chlorinated solvents,

- pump and treat of contaminated groundwater,

- in situ aerobic biological dechlorination, and

- surfactant flushing.

Costs for these technologies, some of which require more than 30 years to remediate a site, are between $\$ 25$ and $\$ 75 / y^{3}{ }^{3}$. Lasagna ${ }^{T M}$ is within the range of these competing technologies with an implementation cost (over 3 years) of about $\$ 50 / y^{3} d^{3}$, using the mandrel/tremie-tube method of emplacement as proposed for Phase II. 


\section{REGULATORYIPOLICY ISSUES}

\section{Regulatory Considerations}

Communication with regulators should be established early in the development process for new remediation technologies. For the PGDP demonstrations of Lasagna ${ }^{\mathrm{TM}}$, early contact with EPA and state of Kentucky regulators led to determinations that

- no air permits were needed (negligible amounts of TCE would be vaporized by the electrical heating of soil);

- no underground injection permit was needed (water would be recycled from cathode to anode, not injected at depth);

- the soil cleanup standard of $5.6 \mathrm{ppm}$ achieved the maximum contaminant level ( $5 \mathrm{ppb}$ in water) for TCE at the point of exposure;

- the PGDP security fence could be established as the point of exposure for consumption, thereby serving as the basis for the soil cleanup standard; and

- the demonstration would be granted a categorical exclusion under the National Environmental Policy Act (no environmental impact).

\section{Safety, Risks, Benefits, and Community Reaction}

The intermediate degradation products of TCE reduction should be monitored as well as TCE. Water cleanup targets for cis-dichloroethylene $(70 \mathrm{ppb})$ and vinyl chloride $(2 \mathrm{ppb})$ suggest that vinyl chloride will be the more significant health risk concern.

No permit was needed for the electrical installation, but site inspection by a qualified electrical engineer and lock-out/tag-out training for site personnel were required 


\section{LESSONS LEARNED}

\section{Design Issues}

- Phase I results indicate that electroosmosis can flush TCE from clay soil with the passage of two or three pore volumes of water between adjacent treatment zones. More flushing may be required when greater amounts of DNAPL are present.

- Partial plugging of the cathode siphon tubes during the first month of Phase I testing caused water to overflow the cathode wicks. Pinched tubes can be prevented by better design or more robust tubing.

\section{Implementation Considerations}

- Iron corrosion was the dominant anode reaction for the first 3 months of power application, but water electrolysis apparently occurred in the 4th month, lowering the pH near the anode to 2-3. Electrode polarity reversal may be a desirable option to mitigate this effect for long-term power applications.

\section{Technology Limitations/Needs for Future Development}

- Phase II testing will address a number of design and operational issues, including treatment zone spacing, effectiveness of zero-valent iron degradation of TCE when used in conjunction with electroosmosis, and emplacement of vertical granular electrodes and treatment zones to 45-ft depths by the mandrel/tremie-tube method. Greater amounts of DNAPL TCE are also anticipated, possibly requiring more electroosmotic flushing than was used in Phase $\mathrm{I}$.

- Lasagna ${ }^{\mathrm{TM}}$ is potentially capable of treating multiple contaminants in soil, but treatment chemistry and procedures will have to be developed to assure compatibility of the treatment processes for individual contaminants.

- Hydraulic fracturing and slurry emplacement of horizontal electrodes and treatment zones offer promise for Lasagna ${ }^{\mathrm{TM}}$ treatment of deep zones of contamination, but issues of good electrical contact to electrodes and trapping of gases generated by electrolysis need to be resolved by the technology developers, EPA and the University of Cincinnati.

- Bioremediation in Lasagna ${ }^{\mathrm{TM}}$ treatment zones is an option that has been demonstrated in the laboratory by Monsanto and is now being evaluated by EPA, Monsanto, and others for field implementation. This will require further development.

\section{Future Technology Selection Considerations}

- Lasagna ${ }^{\mathrm{TM}}$ is a modular technology, and plans to remediate the entire PGDP Cylinder Drop Test Area (SWMU 91) assume that the Phase lla configuration can be used in six adjacent, like-sized areas that would be treated concurrently in Phase II.

- Site evaluations and negotiations are proceeding with Department of Defense sites interested in collaborating with the consortium on a demonstration of the horizontal configuration of Lasagna ${ }^{\mathrm{TM}}$, probably using bioremediation in the treatment zones.

- improvements in treatment zone emplacement technology may be possible through the use of cheaper materials with the mandrel/tremie-tube technology or through the use of jet grouting. DuPont will explore these options as part of the Phase II development work. 


\section{APPENDIX A}

\section{REFERENCES}

Athmer, C. J., et al. 1996. Large Scale Field Test of the Lasagna ${ }^{T M}$ Process, Monsanto draft Topical Report.

Brackin, M. J., et al. 1996. Development of Degradation Processes, Monsanto draft Topical Report.

Brodsky, P. H., and S. V. Ho 1995. In Situ Remediation of Contaminated Soils, U.S. Patent 5,398,756, issued March 21, 1995.

Clausen, J. L., et al. n.d. DNAPL Site Characterization and Lasagna ${ }^{T M}$ Technology Demonstration at Solid Waste Management Unit 91 of the Paducah Gaseous Diffusion Plant, Paducah, KY, DOE report KY/EM-128 (to be published).

Dev, H., and J. M. Phelan 1996. "In Situ Electrical Heating for the Decontamination of Soil," presented at the American Power Conference, Chicago, III., April 10, 1996 (to be published).

DOE (U.S. Department of Energy) 1995a. "Dynamic Underground Stripping," Innovative Technology Summary Report, DOE-EM-0271.

DOE (U.S. Department of Energy) 1995b. "Six-Phase Soil Heating," Innovative Technology Summary Report, EM/OST.

DOE (U.S. Department of Energy) 1996. "In Situ Enhanced Soil Mixing," Innovative Technology Summary Report, EM/OST.

Freeze, R. A., and D. B. McWhorter. "A Framework for Assessing Risk Reduction Due to DNAPL Mass Removal from Low Permeability Soils," in in Situ Remediation of DNAPL Compounds in Low Permeability Media: Rate/transport, in Situ Control Technologies, and Risk Reduction, DOE-EM-xxxx (to be published).

Gates, D. D., N. E. Korte, and R. L. Siegrist. "In Situ Chemical Degradation of DNAPLs in Contaminated Soils \& Sediments," in In Situ Remediation of DNAPL Compounds in Low Permeability Media: Rate/transport, In Situ Control Technologies, and Risk Reduction, DOE-EM-xxxx (to be published).

Ho, S. V. "Electro-osmosis Remediation of DNAPLs in Low Permeability Soils," in In Situ Remediation of DNAPL Compounds in Low Permeability Media: Rate/transport, In Situ Control Technologies, and Risk Reduction, DOE-EM-xxxx (to be published).

Ho, S. V., and P. H. Brodsky 1995. In Situ Remediation of Contaminated Heterogeneous Soils, U.S. Patent 5,476,992, issued December 19, 1995.

Ho, S. V., et al. 1993. "Innovative Soil Remediation Technology," in Proceedings, American Chemical Society I\&EC Special Symposium, Atlanta, Ga., Sept. 27-29, 1993, pp. 731-734.

Ho, S. V., et al. 1995a. "Integrated In-Situ Soil Remediation Technology-The Lasagna Process," Environ. Sci. Tech., 29(10). 
Ho, S. V., et al. 1995b. "Development of the Integrated In-Situ Lasagna Process," in Proceedings of the Environmental Technology Through Industry Partnership Conference, vol. II., ed. V. P. Kothari, DOE/METC-96/1021, vol. 2, DE96000552, pp. 455-472.

Ho, S. V., et al. 1996. Laboratory and Pilot Scale Experiments of Lasagna ${ }^{\mathrm{TM}}$ Process, Monsanto draft Topical Report.

Hughes, B. M., et al. 1996. Evaluation of TCE Contamination Before and After the Field Experiment, Monsanto draft Topical Report.

Quinton, G., et al. 1996. Cost Analysis, Monsanto draft Topical Report.

Odom, J. M. 1996. Lab-scale Development of Microbial Degradation Process, Monsanto draft Topical Report.

Orth, R. G., and D. E. McKenzie 1996. TCE Degradation Using Non-Biological Methods, Monsanto draft Topical Report.

Shapiro, A. P. 1996. Electrokinetic Modeling, Monsanto draft Topical Report.

Shapiro, A. P., et al. 1996. TCE Degradation Using Non-Biological Methods, Monsanto draft Technical Report.

Shoemaker, S. H., et al. 1996. Evaluation of Treatment Zone Formation Options, Monsanto draft Technical Report. 


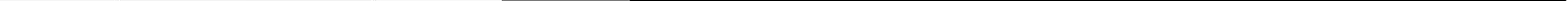


